\title{
Nodular thyroid disease and thyroid malignancy: Experience at Polokwane Mankweng Hospital Complex, Limpopo Province, South Africa
}

\author{
M M Z U Bhuiyan, FRCSG, MMed; A Machowski, MD, PhD \\ Department of General Surgery, Polokwane Mankweng Hospital Complex and Faculty of Health Sciences, University of Limpopo, \\ Polokwane campus, Limpopo Province, South Africa
}

Corresponding author: M M Z Bhuiyan (bhuiyanmirza@gmail.com)

\begin{abstract}
Background. Nodular thyroid disease is common throughout the world. Numbers of patients with goitre are increasing worldwide, as also noted in Limpopo Province, South Africa (SA). Globally, thyroid nodules have been reported in 4 - 7\% of the population on neck palpation and in $30-50 \%$ by ultrasonography.

Objectives. To review the profile of thyroid disease in patients with goitre presenting to the Department of Surgery at Polokwane Mankweng Hospital Complex (PMHC), Limpopo, SA, to characterise the pattern of malignancy in patients with goitre, and to determine the most common thyroid cancer. Method. A 6-year retrospective study (2003 - 2008) of all patients with thyroid nodules who underwent thyroid surgery at PMHC.

Results. The study group included 90 patients (mean age 45 years, range 4 - 80). The male-to-female ratio was 1:17 (5 men, 85 women). Of these patients, $80(89.9 \%)$ had benign lesions, of which 52 (57.8\% of the total) were adenomas, $25(27.8 \%)$ multinodular goitres (MNGs), 2 (2.2\%) hyperplastic nodules and $1(1.1 \%)$ Hashimotos thyroiditis. Ten patients $(11.1 \%)$ had malignant lesions (7 follicular carcinomas and 3 papillary carcinomas), of which 2 were found in MNGs.

Conclusions. Adenoma and MNG were the predominant non-malignant conditions (85.6\%). The prevalence of thyroid cancer in our study was $11.1 \%$, and of all 90 patients, $7.8 \%$ had follicular carcinoma. The risk of malignancy in MNG was $8.9 \%$. Rates of thyroid nodules and carcinoma were highest in women aged 41 - 60 years. We advocate that total thyroidectomy be considered for MNG, because MNG can harbour incidental carcinoma.

S Afr Med J 2015;105(7):570-572. DOI:10.7196/SAMJnew.7885
\end{abstract}

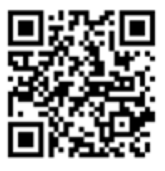

Nodular thyroid disease is common throughout the world, and the incidence has been rising in recent decades. Worldwide, thyroid nodules have been reported in 4 - 7\% of the population on neck palpation and in $30-50 \%$ when investigated by ultrasonography. ${ }^{[1,2]}$ Usually patients with nodular thyroid disease present to a surgical clinic with a neck mass, with or without toxic symptoms, with pressure symptoms or for cosmetic reasons. Treatment options depend on the cause and the clinical presentation and include medication, radioactive iodine and surgery.

Thyroid nodules can be benign (adenoma, nodules of multinodular goitres (MNGs), or localised thyroiditis, including autoimmune disease and cysts) or malignant (papillary adenocarcinoma, follicular adenocarcinoma, medullary carcinoma, undifferentiated carcinoma or lymphoma).

In the hands of experienced surgeons, surgery for nodular thyroid disease has low mortality and morbidity. ${ }^{[3]}$ Operations include lobectomy/hemithyroidectomy, subtotal thyroidectomy and total thyroidectomy.

There has been no formal study on these diseases in Limpopo Province, South Africa (SA), which has a population of 5.5 million.

\section{Objectives}

To review the profile of thyroid disease in patients with goitre who presented to the Department of Surgery at Polokwane Mankweng Hospital Complex (PMHC), tertiary hospitals in Limpopo, to characterise the pattern of malignant disease in patients presenting with goitre, and to determine the most common thyroid cancer in the Limpopo population study group.

\section{Methods}

A 6-year retrospective study (2003 - 2008) of all patients with thyroid nodules who underwent thyroid surgery at PMHC was done. All the patient files were reviewed, and cases in which histological results were not available were excluded. Data were collected from the theatre and hospital information systems, the National Health Laboratory Service and the patient files.

\section{Results}

Of 117 patient files, 27 lacked histological results and were excluded from the study. The study group therefore consisted of 90 patients, ranging in age from 4 to 80 years (mean 45); 85 (94.4\%) were women and 5 men (5.6\%) (male-to-female ratio 17:1).

Thyroid function tests were done in all cases, ultrasound scans in 42 , isotope nuclear scans in 59 and fine-needle aspiration cytology (FNAC) in 11. The histopathological diagnoses in all 90 patients are shown in Table 1. Indications for surgery were cosmetic reasons, suspected malignancy, and compression of adjacent areas.

Surgical operations included 53 lobectomies, 31 subtotal thyroidectomies and 6 total thyroidectomies. There were no operative deaths. Ten patients $(11.1 \%$ of the total) had malignant lesions (7 follicular

Table 1. Histopathological diagnoses of thyroid lesions $(N=90)$

\begin{tabular}{ll}
\hline Histological findings & $\begin{array}{l}\text { Patients } \\
\boldsymbol{n}(\%)\end{array}$ \\
\hline Benign conditions & \\
$\quad$ Adenoma & $52(57.8)$ \\
MNG & $25(27.8)$ \\
Hyperplastic nodules & $2(2.2)$ \\
Hashimoto's thyroiditis & $1(1.1)$ \\
Subtotal & $80(88.9)$ \\
Malignant conditions & \\
Follicular carcinoma & $7(7.8)$ \\
$\quad$ Papillary carcinoma & $3(3.3)$ \\
Subtotal & $10(11.1)$
\end{tabular}




\begin{tabular}{|c|c|c|c|}
\hline Demographic & $\begin{array}{l}\text { Benign disease } \\
n(\%)\end{array}$ & $\begin{array}{l}\text { Malignant disease } \\
n(\%)\end{array}$ & $p$-value \\
\hline Gender & & & $0.453^{*}$ \\
\hline Males & $4 / 5(80.0)$ & $1 / 5(20.0)$ & \\
\hline Females & $76 / 85(89.4)$ & $9 / 85(10.6)$ & \\
\hline Age group (years) & & & $0.259^{*}$ \\
\hline$\leq 20$ & 1 & - & \\
\hline $21-40$ & 27 & $1 / 28(3.6)$ & \\
\hline $41-60$ & 43 & $7 / 50(14.0)$ & \\
\hline$>60$ & 9 & $2 / 11(18.2)$ & \\
\hline *Fisher's exact test. & & & \\
\hline
\end{tabular}

carcinomas and 3 papillary carcinomas). There were 80 patients (88.9\%) with benign lesions, of which $52(57.8 \%$ of the total) were adenomas, 25 (27.8\%) MNGs, 2 (2.2\%) hyperplastic nodules and 1 (1.1\%) Hashimoto's thyroiditis. Two papillary carcinomas were found in MNGs (8.0\% of MNGs).

Of all the patients, $7.8 \%$ had follicular carcinoma (7 cases). Adenomas and MNGs were the most common non-malignant conditions, occurring in 77 patients (85.6\%). In our study, thyroid nodules, whether benign or malignant, occurred more frequently in women $(94.4 \%)$ than in men. The age group most affected was 41 - 60 years (Table 2).

\section{Discussion}

The prevalence of thyroid nodules is rising globally. According to the World Health Organization, at least 1.6 billion people are at risk of iodine deficiency disorders, and of these 655 million are affected by goitre. ${ }^{[4]}$ Most thyroid nodules are benign. The worldwide prevalence of MNG in the general population is estimated to be $4-7 \%$, and these lesions are often caused by iodine deficiency. ${ }^{[5]}$ The incidence of thyroid malignancy ranges from $0.9 \%$ to $20.5 \%$ in different parts of the world. ${ }^{[6,7]}$ Globally, the most common thyroid cancer is papillary carcinoma. ${ }^{[8,9]}$ Follicular carcinoma, while relatively less frequent, is reported to be more common in iodine-deficient areas where MNG is endemic. ${ }^{[10-17]}$

Thyroid cancer is the most common endocrine carcinoma, and the risk factors for malignancy are age $<30$ or $>60$ years, male gender ( $8 \%$ males v. $4 \%$ females), ${ }^{[2,18]}$ and a history of irradiation to the head and neck. ${ }^{[19]}$

Limpopo Province is located far from the sea, and the iodine content in the diet is low. Our $11.1 \%$ rate of thyroid cancer in Limpopo is consistent with the literature. ${ }^{[6,7]}$ In our study, the predominant thyroid cancer was follicular carcinoma $(7.8 \%$ of patients), comparable to reports from Durban and Burkina Faso. ${ }^{[20-22]}$ The two cancers in MNGs in our study were papillary carcinomas. The risk of malignancy in cases of MNG in our study was $8.9 \%$, similar to findings reported in the literature of $2-12 \% \cdot \cdot^{[6,8,10,23-27]}$ Although there were few males in our study, figures indicate that men are at twice the risk of developing cancer compared with females. FNAC was not reliable in Limpopo; as a result we could not use it regularly, so it is difficult to draw conclusions in this regard. Cytology reports for our 11 patients who underwent FNAC fell into categories $1-3$ of the Bethesda classification. ${ }^{[28]}$ On histological examination, these lesions were found to be non-malignant. The value of FNAC in thyroid cancers and thyroid nodules is well established, ${ }^{[29-31]}$ including at PMHC. It is known that the rate of false-negative results for FNAC ranges from $0.7 \%$ to $2.2 \%$ if ultrasound-guided FNAC is used, ${ }^{[2,33]}$ the rate rising to $44.7 \%$ without ultrasonography. ${ }^{[10,21,34-39]}$ FNAC significantly reduces the number of unnecessary operations, ${ }^{[30,31,40]}$ but the problem of its missing malignant lesions remains unsolved.

Five of our 59 patients who had isotope nuclear scans were suspected to have a malignant lesion, but in only one case was carcinoma histologically confirmed, which is similar to previously reported findings. ${ }^{[4]}$ Radioisotope investigations for malignant disease have an important role, but only if they are taken together with clinical findings and other investigations such as ultrasonography, FNAC, computed tomography, magnetic resonance imaging or positron emission tomography. ${ }^{[7,42]}$

Benign thyroid disorders are common, and often affect younger females. Subtotal thyroidectomy/hemithyroidectomy are the surgical procedures most frequently offered ${ }^{[2,43,44]}$ In our study the majority of patients were females, in whom benign conditions predominated; the operations performed were either lobectomy or subtotal thyroidectomy.

The approach to the surgical management of benign goitre is progressively becoming more radical owing to the risk of recurrent goitre $^{[3]}$ and the safety of surgery. ${ }^{[30,45-48]}$ Furthermore, the rate of incidental malignancy in MNG is high ( $8.9 \%$ in our study), and re-operation for recurrent goitre following subtotal thyroidectomy is associated with a significantly increased risk of permanent recurrent laryngeal nerve injury. ${ }^{[48]}$

\section{Conclusions}

Adenoma and MNG were the most common non-malignant conditions in our study (85.6\%). The prevalence of thyroid cancer in our study was $11.1 \%$, and of all the lesions $7.8 \%$ were follicular carcinomas. Malignant lesions were found in $8.9 \%$ of patients with MNG. We advocate that total thyroidectomy be considered for MNG because of the risk of incidental carcinoma.

Acknowledgements. We are grateful to Dr B Interewicz and Mrs Maggi Landman for their contribution to data collection, and to Dr F L M Hyera for his valuable comments on this manuscript. We thank Mr S Ntuli for statistical assistance.

\section{References}

1. Pang H-N, Chen C-M. The incidence of cancer in nodular goiters. Ann Acad Med Singapore 2007;36(4):241-243

2. Belfiore A, La Rosa GL, Padova G, Sava L, Ippolito O, Vigneri R. The frequency of cold thyroid nodules 2. Belfiore A, La Rosa GL, Padova G, Sava L, Ippolito O, Vigneri R. The frequency of cold thyroid nodules
and thyroid malignancies in patients from an iodine-deficient area. Cancer 1987;60(12):3096-3102. [http://dx.doi.org/10.1002/1097-0142(19871215)60:12<3096::AID-CNCR2820601240>3.0.CO;2-V]

3. Schmitz-Winnenthal FH, Schimmack S, Lawrence B, et al. Quality of life is not influenced by the extent of surgery in patients with benign goiter. Langenbecks Arch Surg 2011;396(8):1157-1163. [http://dx.doi.org/10.1007/s00423-011-0822-7]

4. WHO reaffirms goal for sustainable IDD elimination. IDD Newsletter 1996;12(7):1-3.

5. Bron IP, O'Brien CJ. Total thyroidectomy for clinically benign disease of the thyroid gland. Br J Surg 2004;91(5):569-574. [http://dx.doi.org/10.1002/bjs.4507]

Najum ul Haq R, Ali Khan B, Ahmed Chaudhry I. Prevalence of malignancy in goiter - a review of 718 thyroidectomies. J Ayub Med Coll Abbottabad 2009;21(4).315-21

7. Czepczyński R. Nuclear medicine in the diagnosis of benign thyroid diseases. Nucl Med Rev Cent East Eur 2012;15(2):113-119.

8. Hanumanthappa MB, Gopinathan S, Rithin S, et al. Incidence of malignancy in multi-nodular goitre: A prospective study at a tertiary academic centre. J Clin Diagn Res 2012;6(2):267-270. [http://dx.doi. A prospective study at a terticy
org/ JCDR/2012/4048:1955]

9. Pisanu A, Reccia I, Nardello O, Uccheddu A. Risk factors for nodal metastasis and recurrence among patients with papillary thyroid microcarcinoma: Differences in clinical relevance between nonincidental and incidental tumors. World J Surg 2009;33(3):460-468. [http://dx.doi.org/10.1007/ 000268-008-9870-8]

10. Bombil I, Bentley A, Kruger D, Luvhengo TE. Incidental cancer in multinodular goitre post thyroidectomy. S Afr J Surg 2014;52(1):5-9. [http://dx.doi.org/ 10.7196/SAJS.1970]

11. Woodruff SL, Arowolo OA, Akute OO, et al. Global variation in the pattern of differentiated thyroid cancer. Am J Surg 2010;200(4):462-466. [http://dx.doi.org/10.1016/j.amjsurg.2010.03.009]

12. Thyroid Cancer. American Cancer Society. Updated 20 January 2012. http://www.cancer.org/acs/ groups/cid/documents/webcontent/003144-pdf.pdf (accessed 8 March 2012).

13. Takashima S, Sone S, Takayama F, et al. Papillary thyroid carcinoma: MR diagnosis of lymph node metastasis. AJNR Am J Neuroradiol 1998;19(3):509-513.

14. Doherty G. Current Diagnosis and Treatment Surgery. 13th ed. (Lange Current Series). New York: McGraw-Hill Medical, 2009. 
15. Sugitani I, Kasai N, Fujimoto Y, Yanagisawa A. A novel classification system for patients with PTC: Addition of the new variables of large (3cm or greater) nodal metastases and reclassification during the
follow-up period. Surgery 2004;135(2):139-148. [http://dx.doi.org/10.1016/S0039-6060(03)00384-2]

16. Rosai J, Carcangiu ML, DeLellis RA. Tumors of the thyroid gland. Atlas of Tumor Pathology. 3rd series, fas 5. Washington, DC: Armed Forces Institute of Pathology, 1992:21-48.3

17. Correa P, Chen VW. Endocrine gland cancer. Cancer 1995;75(1 suppl):338-352.

18. Kumar H, Daykin J, Holder R, Watkinson JC, Sheppard MC, Franklyn JA. Gender, clinical finding and serum thyrotropin measurements in the prediction of thyroid neoplasia in 1005 patients presenting with thyroid enlargement and investigated by fine-needle aspiration cytology. Thyroid 1999;9(11):1105-1109. http://dx.doi.org/10.1089/thy.1999.9.1105

19. Polyzos SA, Kita M, Avramidis A. Thyroid nodules - stepwise diagnosis and management. Hormones 2007;6(2):101-119.

20. Mulaudzi TV, Ramdial PK, Madiba TE, Callaghan RA. Thyroid carcinoma at King Edward VIII Hospital, Durban, South Africa. East Afr Med J 2001:78(5):242-245, [http://dx.doi.org/10.4314/eamj. v78i5.9046]

21. Rumstadt B, Klein B, Kirr H, Kaltenbach N. Thyroid surgery in Burkina Faso, West Africa: Experience from a surgical help program. World J Surg 2008;32(12):2627-2630. [http://dx.doi.org/10.1007/ s00268-008-9775-6]

22. Edino ST, Mohammed AZ, Ochicha O, Malami SA, Yakubu AA. Thyroid cancers in nodular goiters in Kano, Nigeria. Niger J Clin Pract 2010;13(3):298-300.

23. Morris LF, Ragavendra N, Yeh MW. Evidence-based assessment of the role of ultrasonography in the management of benign thyroid nodules. World J Surg 2008;32(7):1253-1263. [http://dx.doi. org/10.1007/s00268-008-9494-z]

24. Memon W, Khanzada TW, Samad A, Kumar B. Incidence of thyroid carcinoma in multinodular goiters. Rawal Medical Journal 2010;35(1):65-67.

25. Bradly DP, Reddy V, Prinz RA, Gattuso P. Incidental papillary carcinoma inpatients treated surgically for benign thyroid diseases. Surgery 2009;146(6):1099-1104. [http://dx.doi.org/10.1016/j. surg.2009.09.025]

26. Benzarti S, Miled I, Bassoumi T, et al. Thyroid surgery (356 cases): The risks and complications. Rev Laryngol Otol Rhinol (Bord) 2002;123(1):33-37.

27. Prades JM, Dumollard JM, Timoshenko A, et al. Multi-nodular goitre: Surgical management and histopathological findings. Eur Arch Otorhinolaryngol 2002;259(4):217-221.

28. Cibas ES, Ali SZ. The Bethesda System for reporting thyroid cytopathology. Am J Clin Pathol 2009;132(5):658-665. [http://dx.doi.org/10.1309/AJCPPHLWMI3JV4LA]

29. Rosen JE, Stone MD. Contemporary diagnostic approach to the thyroid nodule. J Surg Oncol 2006;94(8):649-661. [http://dx.doi.org/10.1002/jso.20701]

30. Efremidou EI, Papageorgiou MS, Liratzopoulos N, Manolas KJ. The efficacy and safety of total thyroidectomy in the management of benign thyroid disease: A review of 932 cases. Can J Surg 2009;52(1):39-44. PMID: 19234650

31. Lin J. Thyroid cancer in thyroid nodules diagnosed using ultrasonography and fine needle aspiration cytology. J Med Ultrasound 2010;18(3):91-104. [http://dx.doi.org/10.1016/S0929-6441(10)60014-8]

32. Lowhagen T, Granberg PO, Lundell G, Skinnari P, et al. Aspiration biopsy cytology (ABC) in nodule of the thyroid gland suspected to be malignant. Surg Clin North Am 1979;59(1):3-18. [http://dx.doi. org/10.1308/003588406X149147]
33. Grant CS, Hay ID, Gough IR, et al. Long term follow-up of patients with benign thyroid: Fine needle aspiration cytologic diagnosis. Surgery 1989;106(6):980-985

44. Mistry SG, Mani N, Murthy P. Investigating the value of fine needle aspiration cytology in thyroid cancer. J Cytol 2011;28(4):185-190. [http://dx.doi.org/10.4103/0970-9371.86345]

35. Perros P, ed. Report of the Thyroid Cancer Guidelines Update Group: Guidelines for the Management of Thyroid Cancer. 2nd ed. London: Royal College of Physicians, 2007.

36. Cobin RH, Gharib H, Bergman DA, et al. AACE/AAES medical/surgical guidelines for clinical practice: Management of thyroid carcinoma. American Association of Clinical Endocrinologists. American College of Endocrinology. Endocr Pract 2001;7(3):202-220.

37. Kopald KH, Layfield LJ, Mohrmann R, Foshaq LJ, Giuliano AE. Clarifying the role of fineneedle aspiration cytologic evaluation and frozen section examination in the operative management of thyroid cancer. Arch Surg 1989;124(10):1201-1205. [http://dx.doi.org/ 10.1001/ archsurg.1989.01410100107018.

38. Gharib H. Fine-needle aspiration biopsy of thyroid nodules: Advantages, limitations, and effect. Mayo Clin Proc 1994;69(1):44-49.

39. Jeffrey PB, Miller TR. Fine-needle aspiration cytology of the thyroid. Pathology (Phila) 1996;4(2):319-335.

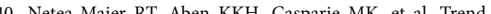
carcinoma in the Netherlonds betwen 1989 and 2003: Conchtion with thyrid carcinoma in the Nethe aspiration cytology and

41. Sabel MS, Staren ED, Gianakakis LM, Dwarakanathan S, Prinz RA. Effectiveness of thyroid scan in evaluation of the solitary thyroid nodule. Am Surg 1997;63(7):660-663

42. Khanzada TW, Memon W, Kumar B, Samad A. Thyroid scintigraphy: An overused investigation Gomal Journal of Medical Sciences 2009;7(1):39-41.

43. Saaiq M, Shah SA, Zubair M. Clinical audit of the presentation and outcome of benign thyroi disorders in a tertiary care setting in Pakistan. J Pak Med Assoc 2013;63(9):1172-1175.

44. Hossain MM, Haque MR, Rashid A, et al. Surgical management of thyroid diseases - a study of 78 cases. Mymensingh Med J 2002;11(1):6-8.

45. Colak T, Akca T, Kanik A, Yapici D, Avdin S. Total versus subtotal thyroidectomy for the managemen of benign multinodular goiter in an endemic region. Aust N Z I Surg 2004;74(11):974-978. [http:// dx.doi.org/10.1111/j.1445-1433.2004.03139.x]

46. Gál I, Solymosi T, Lukács-Tóth G, Wéber G. [Effectiveness and safety of total thyroidectomy in the management of benign multinodular goiters]. Magy Seb 2013;66(5):245-249. [http://dx.doi org/10.1556/MaSeb.66.2013.5.3]

47. Rudolph N, Dominguez C, Beaulieu A, de Wailly P, Kraimps JL. The morbidity of reoperative surger for recurrent benign nodular goitre: Impact of previous unilateral thyroid lobectomy versus subtotal thyroidectomy. J Thyroid Res 2014;2014:231857. [http://dx.doi.org/10.1155/2014/231857]

48. Barczyński M, Konturek A, Hubalewska-Dydejczyk A, Gołkowski F, Cichoń S, Nowak W. Five-yea follow-up of a randomized clinical trial of total thyroidectomy versus Dunhill operation versu bilateral subtotal thyroidectomy for multinodular nontoxic goiter. World J Surg 2010;34(6):1203-1213 [http://dx.doi.org/10.1007/s00268-010-0491-7]

Accepted 3 April 2015 